\title{
Comparison of in vitro Characteristics of Leukodepleted Red Blood Cells (RBCs) Derived from Apheresis: Impact of Filter Performance
}

\author{
Stela M. Radojska Susanne M. Picker Birgit S. Gathof \\ Transfusion Medicine, University of Cologne, Germany
}

\author{
Key Words \\ RBC filtration - Filter performance - Apheresis RBCs . \\ Baxter Amicus - Baxter Alyx · Haemonetics MCS+ . \\ Gambro Trima Accel
}

\section{Summary}

Background: Novel apheresis systems allow collection of packed red blood cells (RBCs) either by double RBC apheresis (2-RBCA) or along with platelet (PLT) concentrates (RBCPLT). The objective of this study was to evaluate filtration performance in connection with in vitro storage quality of filtered RBCs derived from the devices Baxter Amicus (AM), Baxter Alyx (AX), Haemonetics MCS Plus (MCS+) and Gambro Trima Accel (TA). Materials and Methods: 66 2-RBCA (15 $\mathrm{AX}, 10 \mathrm{MCS}+, 8 \mathrm{TA}$ ) and $33 \mathrm{RBC}-\mathrm{PLT}$ collections (15 AM, 9 $\mathrm{MCS}+, 9 \mathrm{TA}$ ) were analyzed. RBC filtration was performed at room temperature within 2-4 h of collection using white blood cell (WBC) reduction filters either integrated in the disposable sets or provided by a filtration device. In vitro parameters were measured after filtration and after 42 days of storage. Results: Except for 1 paired AX unit, all RBCs contained residual WBCs of $<1 \times 10^{6} /$ unit. TA provided the best log reduction in WBCs and PLTs but demonstrated the longest filtration times and smallest $\mathrm{RBC}$ recoveries. $\mathrm{AX}$ and MCS+ had significantly shorter filtration times than AM, however, AM obtained the best RBC recoveries. After filtration, all packed RBCs showed similar in vitro characteristics. At the end of storage, lower values for hemolysis (TA) and ATP preservation (AX) were related to the post-filtration WBC amount, with TA demonstrating the lowest and AX the highest values. Conclusion: While differences in RBC loss were noted, satisfactory filter performance in terms of WBC and PLT removal was observed with most RBC units. In $A X$ procedures, leukodepletion could be improved.

\author{
Schlüsselwörter \\ Erythrozytenfiltration · Filterleistung · \\ Aphereseerythrozyten - Baxter Amicus - Baxter Alyx . \\ Haemonetics MCS+ · Gambro Trima Accel
}

\section{Zusammenfassung}

Hintergrund: Neue Apheresesysteme bieten die Möglichkeit, Erythrozytenkonzentrate (EK) entweder als Doppel-EK oder zusammen mit Thrombozytenkonzentraten (TK) zu sammeln. Ziel dieser Studie war es, Lagerungseigenschaften von Apherese-EK im Zusammenhang mit der Filterleistung verschiedener Apheresegeräte (Amicus (AM) und Alyx (AX) von Baxter, MCS Plus (MCS+) von Haemonetics und Trima Accel (TA) von Gambro prospektiv zu vergleichen. Material und Methoden: 66 EK aus Doppel-EK- (15 AX, $10 \mathrm{MCS}+, 8$ TA) und 33 EK aus kombinierter EK-TK-Sammlung (15 AM, 9 MCS+, 9 TA) wurden analysiert. Die Erythrozytenfiltration wurde innerhalb von 2-4 h nach Entnahme bei Raumtemperatur durchgeführt. Die dabei benutzten Filter waren entweder im Entnahmeset integriert oder Bestandteil eines zusätzlichen Filtrationssets. In-vitro-Parameter wurden unmittelbar nach der Filtration und nach 42 Tagen Lagerzeit gemessen. Ergebnisse: Bis auf ein AX-Doppel-EK wiesen alle Einheiten weniger als $1 \times 10^{6}$ Leukozyten auf. TA zeigte die beste LogReduktion weißer Blutzellen und Plättchen, gleichzeitig jedoch die längste Filtrationszeit und geringste ErythrozytenRecovery. Die Filtrationszeiten von AX and MCS+ waren signifikant geringer als die von AM. AM erzielte jedoch die beste Erythrozyten-Recovery. Nach der Filtration zeigten alle EK ähnliche In-vitro-Charakteristika. Am Ende der Haltbarkeit fand sich eine Korrelation zwischen Leukozytenkontamination nach Filtration (TA am geringsten, $A X$ am höchsten) und Hämolyse (TA am geringsten) sowie ATP-Gehalt (AX am geringsten). Schlussfolgerung: Trotz unterschiedlicher Erythrozytenverluste war die Filterleistung in Bezug auf Leukozyten- bzw. Plättchenreduktion in den meisten Einheiten zufriedenstellend. Eine Verbesserung der Leukozytendepletionstechnik könnte für AX-Verfahren empfohlen werden.

\begin{tabular}{ll}
\hline KARGER & ๑ 2006 S. Karger GmbH, Freiburg \\
Fax +49 7614520714 & Accessible online at: \\
$\begin{array}{l}\text { E-mail Information@Karger.de } \\
\text { www.karger.com }\end{array}$ & www.karger.com/tmh
\end{tabular}




\section{Introduction}

Modern apheresis devices allow the collection of packed red blood cells (RBCs) as double units or along with platelets (PLTs) or plasma. Automated RBC collection has several advantages compared to manual $\mathrm{RBC}$ preparation: The possibility of collecting several blood products from the same donor in a single donation may help to counteract the problem of increasing transfusion demands and shrinking donor pools [1-5]. From the donor's point of view, automated RBC collection results in better fluid balance and is less often associated with vasovagal reactions $[6,7]$. Despite variations in donor hematocrit, apheresis-derived units are better standardized with respect to volume and RBC mass [8]. As apheresis donors are often repeat donors who have a lower prevalence of transmissible diseases [3], the transfusion of apheresis RBCs could reduce the risk of infection, particularly if 2 packed RBCs from the same donor are available to a single recipient. Additionally, automated RBC collection providing complete blood products may reduce costs in transfusion medicine [5].

At present, complete pre-storage white blood cell (WBC) reduction of blood components is a requirement in Europe [9, 10], which necessitates another look at this new technology as different apheresis devices vary in the used filter material and filtration technique. RBC filtration is performed either automatically under pressure or manually by gravity using integrated leukoreduction filters or additional filtration sets. Apart from pre-filtration temperature, hematocrit and WBC load, the effectiveness of pre-storage filtration is affected by several biophysical parameters, such as adherence to filter material and flow rate [11], which differ in pressure and gravity filtration. Because sufficient WBC reduction is one of the main characteristics of modern blood products, this study investigates whether different filtration techniques used in apheresis devices influence the in vitro RBC quality during storage.

\section{Materials and Methods}

\section{Subjects}

66 healthy volunteers were enrolled in this study. All participants gave informed written consent and met the German and European guidelines and requirements for cytapheresis donation [9, 10]. For double RBC apheresis (2-RBCA), a hematocrit of at least $42 \%$ and $140 \mathrm{~g} / \mathrm{l} \mathrm{hemoglobin}$ $(\mathrm{Hb})$ were required. The entry criterion for concurrent collection of RBCs and PLTs (RBC-PLT apheresis) was a minimum of $135 \mathrm{~g} / \mathrm{l} \mathrm{Hb}$ together with at least $180 \times 10^{9} \mathrm{PLTs} / 1$.

\section{RBC Apheresis Collections and Study Design}

A total of 33 2-RBCA collections were performed using Baxter Alyx (AX; Baxter Transfusion Therapies, Deerfield, IL, USA; $\mathrm{n}=15$ ), Haemonetics MCS Plus (MCS+; Haemonetics Corp., Braintree, MA, USA; $\mathrm{n}=10$ ) and Gambro Trima Accel (TA; Gambro BCT, Lakewood, CO,
USA; $\mathrm{n}=8)$. A total of 33 RBC-PLT apheresis collections were performed with Baxter Amicus (AM, $n=15)$, MCS+ $(n=9)$ and TA $(n=9)$. All apheresis procedures were performed with single-needle sets using standard methods according to the manufacturer's instructions. Acid citrate dextrose $\mathrm{A}$ (ACD-A) was used as anticoagulant for all collections. Target yields were programmed to $180 \mathrm{ml}$ absolute RBC mass per unit (with a theoretical hematocrit of $100 \%$ ) and to $3.0 \times 10^{11}$ PLTs per unit. All apheresis collections resulting in 99 RBC units (33 double, 33 single unit RBCs) were completed. All RBCs were maintained at ambient temperature from collection through filtration performed within $4 \mathrm{~h}$ of venipuncture. Filtration performance, RBC characteristics before filtration (except for AX allowing for post-filtration measurements only due to the fully automated process) and after filtration were evaluated for each system using the same standard hematology analyzer (Sysmex K1000; Sysmex Deutschland GmbH, Norderstedt, Germany). In vitro measurement of storage effects on RBC quality was performed on the day of filtration, and then in weekly intervals until storage day 42.

\section{RBC Reconstitution in SAGM Preservative Solution}

All RBCs were resuspended in SAGM (saline adenine glucose mannitol). SAGM was added automatically only with MCS+ and AX, while TA and AM required manual transfer to the collected RBCs using additional disposable sets. For AM, this set (DGR-7225B) consisted of an Asahi in-line WBC reduction filter (Asahi Sepacell filter R3000; Asahi Medical Co. Ltd., Tokyo, Japan), $100 \mathrm{ml}$ SAGM and the final storage container, and was sterilely connected to the RBC reservoir bag using a sterile connection device (Terumo SC201AH; Terumo, Tokyo, Japan). For TA, SAGM was transferred to the collected RBCs after sterile connection of an additional SAGM bag ( $80 \mathrm{ml}, 777962000$, Gambro BCT). This was performed by joining the SAGM disposable and the RBC collection bag via a pre-attached 'infusion thorn' allowing the SAGM solution to flow to the collected RBCs.

\section{RBC Filtration}

RBC filtration disposable tubing sets with integrated RBC leukoreduction filters were provided for AX (R4R 5705 with filter AL2, Asahi Medical Co. Ltd.), MCS+ (2-RBCA with REF 948F with filter RC2H, Pall Biomedical, Portsmouth, UK; PLT-RBC apheresis with REF 946FF with filter RC1H, Pall Biomedical) and TA (2-RBCA with 80550, PLT-RBC apheresis with 80450, each with TLR filtration system, Pall Biomedical). AM required an additional disposable set as described above. AX was the only device performing filtration automatically under pressure immediately after the last return cycle. AM, MCS+ and TA transferred the collected RBCs into reservoir bags. The RBCs collected with MCS+ were hereby automatically resuspended in SAGM solution. After disconnection from the disposable tubing set, the RBC reservoir bag of $\mathrm{MCS}+$ (with the pre-attached filter and storage bags) was stored at room temperature for at least $2 \mathrm{~h}$ before filtration. Filtration was performed by gravity from a height of $2 \mathrm{~m}$. In the case of double RBC units, the whole collection unit passed through a 2-unit RBC leukoreduction filter, whereby the filtered components divided simultaneously into 2 separate RBC units. 2-RBCs harvested with TA were collected in 2 separate reservoir bags. Each of these bags contained its own pre-attached disposable in-line filtration set. After disconnection, SAGM solution was added manually to each of the reservoir bags as described above. The resuspended RBCs were maintained at room temperature for at least $2 \mathrm{~h}$ prior to gravity filtration from a height of $2 \mathrm{~m}$. For AM, after the collected RBCs had been disconnected from the collection set, an additional disposable set was sterilely connected to the RBC reservoir bag as described above. The resuspended RBCs were kept at room temperature for at least $2 \mathrm{~h}$ and then filtered by gravity (from a height of $2 \mathrm{~m}$ ) using the Asahi leukoreduction filter. 
Table 1. Results of WBC filtration (mean \pm SD) of 2-RBCA and RBC-PLT apheresis ${ }^{\mathrm{a}}$

\begin{tabular}{|c|c|c|c|c|c|c|}
\hline & \multicolumn{3}{|l|}{ 2-RBCA } & \multicolumn{3}{|c|}{ RBC-PLT apheresis } \\
\hline & $\begin{array}{l}\text { Alyx } \\
(\mathrm{n}=30)\end{array}$ & $\begin{array}{l}\text { MCS+ } \\
(n=20)\end{array}$ & $\begin{array}{l}\text { Trima Accel } \\
(\mathrm{n}=16)\end{array}$ & $\begin{array}{l}\text { Amicus } \\
(\mathrm{n}=15)\end{array}$ & $\begin{array}{l}\text { MCS+ } \\
(\mathrm{n}=9)\end{array}$ & $\begin{array}{l}\text { Trima Accel } \\
(\mathrm{n}=9)\end{array}$ \\
\hline \multicolumn{7}{|l|}{ Volume, $\mathrm{ml} /$ unit } \\
\hline Before & not done & $602.8 \pm 8.0$ & $297.2 \pm 3.3$ & $346.8 \pm 5.7^{b, c}$ & $301.1 \pm 2.2^{\mathrm{b}, \mathrm{e}}$ & $294.4 \pm 4.0^{c, e}$ \\
\hline After & $281.0 \pm 5.1^{\mathrm{b}}$ & $278.4 \pm 5.5^{\mathrm{b}}$ & $262.8 \pm 6.0$ & $323.2 \pm 5.6$ & $259.8 \pm 4.9^{\mathrm{e}}$ & $259.1 \pm 6.1^{\mathrm{e}}$ \\
\hline Volume recovery, \% & - & $92.4 \pm 1.0$ & $88.2 \pm 1.4^{\mathrm{c}}$ & $93.2 \pm 0.9^{b, c}$ & $86.3 \pm 1.4^{b, e}$ & $88.0 \pm 2.5^{\mathrm{c}, \mathrm{e}}$ \\
\hline Difference between paired units, ml & $1.6 \pm 1.2^{\mathrm{b}}$ & $2.5 \pm 2.9$ & $5.1 \pm 3.1$ & & & \\
\hline \multicolumn{7}{|l|}{ Hematocrit } \\
\hline Before & not done & $52.6 \pm 0.8^{\mathrm{b}}$ & $57.5 \pm 3.3$ & $51.1 \pm 0.7^{b, c}$ & $53.6 \pm 0.5^{\mathrm{b}, \mathrm{e}}$ & $55.6 \pm 1.4^{c, e}$ \\
\hline After & $57.0 \pm 1.8^{\mathrm{c}}$ & $53.2 \pm 1.1$ & $56.6 \pm 2.8^{\mathrm{c}}$ & $53.5 \pm 1.0$ & $54.5 \pm 0.8$ & $56.1 \pm 1.8^{\mathrm{e}}$ \\
\hline \multicolumn{7}{|l|}{ RBC count $\times 10^{12} /$ unit } \\
\hline Before & not done & $1.82 \pm 0.12$ & $1.88 \pm 0.16$ & $1.98 \pm 0.08$ & $1.83 \pm 0.07^{\mathrm{e}}$ & $1.89 \pm 0.12$ \\
\hline After & $1.81 \pm 0.07$ & $1.70 \pm 0.08^{\mathrm{d}}$ & $1.63 \pm 0.15^{\mathrm{d}}$ & $1.91 \pm 0.08$ & $1.61 \pm 0.08^{\mathrm{e}}$ & $1.66 \pm 0.12^{\mathrm{e}}$ \\
\hline RBC recovery, \% & - & $93.5 \pm 2.3$ & $87.0 \pm 6.2^{\mathrm{c}}$ & $96.6 \pm 1.9$ & $87.6 \pm 1.5^{\mathrm{e}}$ & $88.1 \pm 5.4^{\mathrm{e}}$ \\
\hline \multicolumn{7}{|l|}{ RBC mass, ml/unit } \\
\hline Before & not done & $159.8 \pm 3.0$ & $169.2 \pm 9.6$ & $177.8 \pm 3.6$ & $161.5 \pm 0.7^{\mathrm{e}}$ & $163.7 \pm 5.4^{\mathrm{e}}$ \\
\hline After & $160.3 \pm 5.3$ & $149.0 \pm 3.2^{\mathrm{d}}$ & $148.3 \pm 9.4^{\mathrm{d}}$ & $172.5 \pm 4.3$ & $141.6 \pm 2.4^{\mathrm{e}}$ & $145.5 \pm 7.2^{\mathrm{e}}$ \\
\hline RBC loss, \% & - & $6.7 \pm 2.3$ & $12.3 \pm 3.0^{\mathrm{c}}$ & $3.0 \pm 1.7$ & $12.3 \pm 1.6^{\mathrm{e}}$ & $11.1 \pm 3.4^{\mathrm{e}}$ \\
\hline \multicolumn{7}{|l|}{ PLTs per unit } \\
\hline Before $\times 10^{9}$ & not done & $5.54 \pm 1.40^{\mathrm{b}}$ & $43.2 \pm 36.3$ & $16.07 \pm 6.43^{\mathrm{c}}$ & $5.03 \pm 1.24$ & $16.6 \pm 11.9^{c}$ \\
\hline After $\times 10^{5}$ & $0.39 \pm 0.64$ & $1.92 \pm 1.25^{\mathrm{d}}$ & $1.33 \pm 1.82$ & $3.75 \pm 4.96$ & $2.51 \pm 0.71$ & $0.81 \pm 0.81$ \\
\hline PLT removal, \% & - & $61.6 \pm 30.8^{\mathrm{b}}$ & $95.8 \pm 4.8$ & $82.0 \pm 20.1^{\mathrm{c}}$ & $49.7 \pm 7.9$ & $94.1 \pm 6.0^{\mathrm{c}}$ \\
\hline \multicolumn{7}{|l|}{ WBCs per unit } \\
\hline Before $\times 10^{9}$ & not done & $1.89 \pm 0.56$ & $2.36 \pm 1.26$ & $1.85 \pm 0.83$ & $1.30 \pm 0.55$ & $1.65 \pm 0.82$ \\
\hline After $\times 10^{5}$ & $3.56 \pm 3.70$ & $3.52 \pm 1.96$ & $1.44 \pm 0.88$ & $3.54 \pm 2.48$ & $1.78 \pm 0.86$ & $1.61 \pm 0.45$ \\
\hline WBC removal, \% & - & $99.979 \pm 0.014$ & $99.992 \pm 0.007$ & $99.976 \pm 0.023$ & $99.987 \pm 0.007$ & $99.981 \pm 0.027$ \\
\hline WBC $\log$ reduction & - & $3.77 \pm 0.30$ & $4.30 \pm 0.60$ & $3.79 \pm 0.41$ & $3.93 \pm 0.18$ & $3.98 \pm 0.46$ \\
\hline Filtration time, min & $6.2 \pm 0.3^{b, c}$ & $8.6 \pm 0.7^{b, d}$ & $13.3 \pm 1.5^{c, d}$ & $15.5 \pm 0.8^{b, c}$ & $8.2 \pm 1.0^{b, e}$ & $14.0 \pm 2.4^{\mathrm{c}, \mathrm{e}}$ \\
\hline SAGM addition, $\mathrm{ml}$ & $88.3 \pm 0.5^{\mathrm{b}, \mathrm{c}}$ & $99.7 \pm 4.7^{b, d}$ & $71.5 \pm 1.8^{c, d}$ & $93.7 \pm 1.4^{b, c}$ & $77.4 \pm 1.6^{\mathrm{b}, \mathrm{e}}$ & $72.4 \pm 2.0^{c, e}$ \\
\hline
\end{tabular}

a Italic letters illustrate highest or lowest values of all systems.

bignificant compared to Trima Accel.

'Significant compared to MCS+.

dSignificant compared to Alyx.

eSignificant compared to Amicus.

\section{Filtration Performance}

Product samples of RBC concentrates were obtained by sterile connection of a sample pouch comprising a volume of approximately $2 \mathrm{ml}$. Filtration performance was evaluated in respect to $\mathrm{RBC}$ loss and $\mathrm{WBC}$ reduction capacity by recording filtration time, pre- and post-filtration blood cell counts as well as volumes. Pre-filtration hematocrits and cell counts were obtained from all units immediately after SAGM addition except for AX. Here, the fully automated process allowed for post-filtration sampling only. Additional pre-filtration measurements prior to SAGM addition were obtained from AM and TA procedures with manual SAGM addition. The post-filtration WBC count was measured by flow cytometry (FACScan; Becton Dickinson, San Jose, CA, USA) immediately after filtration using kit technology (LeukoCOUNT ${ }^{\circledR}$ test kit, Becton Dickinson). The volume of the RBCs was calculated by dividing the net weight (gross weight minus tare including tubing) of the bags content by the specific gravity for RBCs $(1.06 \mathrm{~g} / \mathrm{ml})$. RBC mass was calculated by multiplying the unit's volume by its hematocrit divided by 100 .

\section{In vitro Measurements}

The effect of storage on RBC quality was determined on the day of filtration and at the end of shelf life (storage day 42). Product samples of approximately $2 \mathrm{ml}$ were collected after sterile connection of a sample pouch. In vitro measurements included hematocrit, total and supernatant (free) $\mathrm{Hb}$ as well as ATP levels, supernatant potassium, glucose, lactate and $\mathrm{pH}$. These measurements were performed by standard procedures [12]. Sterility was verified by microbial culture testing of each RBC unit derived from PLT-RBC collections and of an arbitrarily selected unit from each 2-RBCA.

\section{Statistical Analysis}

The storage data from double and single units obtained by the same system were combined. Standard statistical analysis of the results, such as mean and standard deviation (SD), was performed. Statistical significance of comparisons was evaluated by the Kruskall-Wallis test using commercially available software (SPSS 11.0 for Windows; SPSS Software GmbH, Munich, Germany). In the case of significant differences, paired comparisons were made with the Mann-Whitney-U test after adjusting the significance level using the Bonferoni correction. 


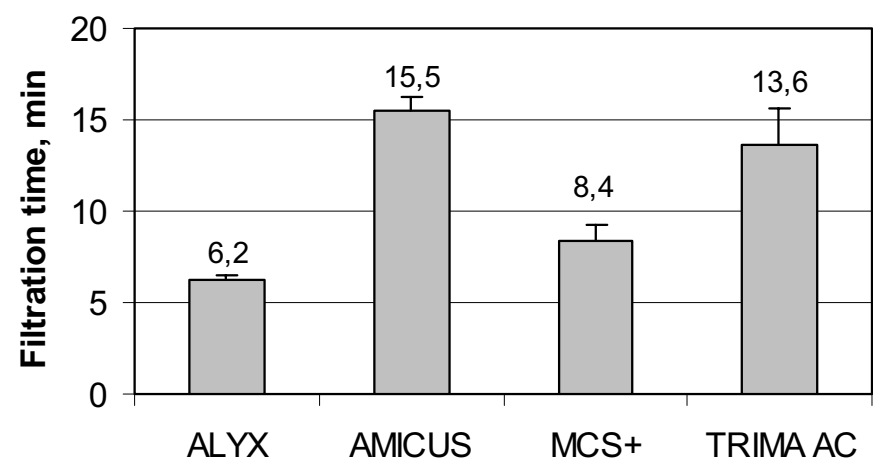

Fig. 1. Filtration time of 4 different apheresis systems. Amicus had the significantly longest and Alyx the significantly shortest filtration time of all systems ( $\mathrm{p}<0.001$ for all 6 possible comparisons).

\section{Results}

The filter performance results of the 4 systems are summarized in table 1 . The data for all procedures combined are illustrated in figures 1-3.

\section{Double RBC Apheresis}

Filtration time was significantly shorter with $\mathrm{AX}$ and significantly longer with TA. After filtration, all except $1 \mathrm{AX}$ unit contained $<1 \times 10^{6}$ WBCs ranging from 0.11 to $1.59 \times 10^{6}, 0.09$ to $0.69 \times 10^{6}$ and 0.01 to $0.25 \times 10^{6} \mathrm{WBCs}$ in AX, MCS+ and TA units, respectively. Post-filtration volumes were similar with MCS+ and AX, while TA attained significantly lower values. The mean volume loss per filtration procedure was $44.7 \pm$ $5.4 \mathrm{ml}$ for MCS $+(22.9 \pm 3.0 \mathrm{ml}$ per paired unit $)$ and $35.1 \pm 4.1$ $\mathrm{ml}$ for TA. No significant change in hematocrit was observed before and after filtration for MCS+ and TA units. Mean postfiltration hematocrits of AX and TA units were significantly higher than that of MCS+, due to the amount of SAGM addition being highest in MCS+ procedures. The maximum percentage of RBC loss for any of the filtration procedures was observed with TA (16.5\%), the minimum with MCS+ $(2.7 \%)$. The mean percentage of RBC and volume recovery was significantly higher for MCS+ as compared to TA. In turn, the post-filtration reductions in WBCs and PLTs were significantly higher for TA, demonstrating the lowest WBC counts of all system, while the highest values were observed with AX. All units passed the bacterial control tests after 42 days of storage.

\section{PLT- RBC Apheresis}

Filtration time was significantly shorter with MCS+ and significantly longer with AM. After filtration, all units contained $<1$ $\times 10^{6}$ WBCs ranging from 0.08 to $0.88 \times 10^{6}, 0.09$ to $0.35 \times 10^{6}$ and 0.05 to $0.41 \times 10^{6} \mathrm{WBCs}$ in AM, MCS+ and TA units, re-

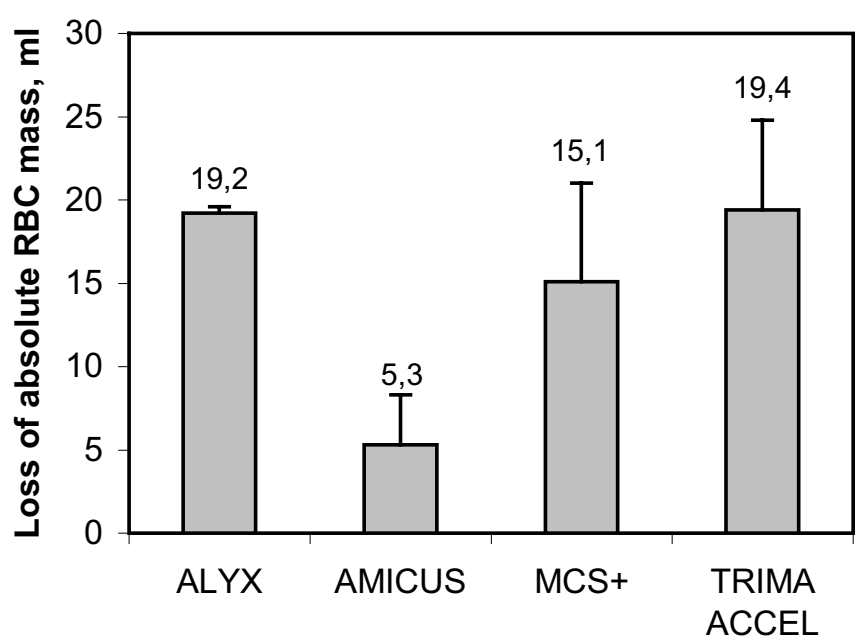

Fig. 2. Loss of absolute $\mathrm{RBC}$ mass $(\mathrm{ml})$ upon filtration of 4 different apheresis systems. Amicus had the significantly lowest filtration related RBC loss of all systems ( $<<0.001)$. Alyx and MCS + were similar to Trima Accel $(\mathrm{p}=0.766, \mathrm{p}=0.052)$, while differences between Alyx and MCS+ were significant $(\mathrm{p}=0.011)$.

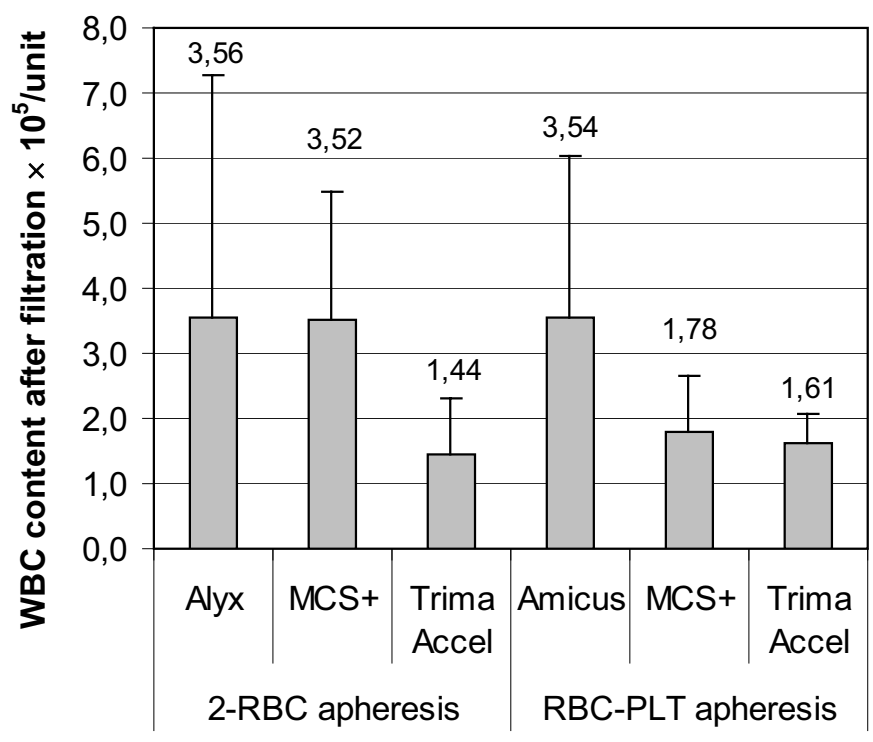

Fig. 3. WBC content after filtration of RBCs collected with 4 different apheresis systems. Trima Accel demonstrated the lowest WBC contamination of all systems. The differences observed between the systems were not significant.

spectively. Post-filtration volumes were similar between MCS+ and TA, while AM attained the significantly highest values. Mean volume loss per filtration procedure was quite different among the systems with AM presenting the lowest $(23.6 \pm 3.3 \mathrm{ml})$ and MCS + the highest values $(41.3 \pm 4.2 \mathrm{ml})$. The mean filtration-related volume loss of TA $(35.3 \pm 7.7 \mathrm{ml})$ was similar to MCS+ but significantly higher than AM. No relevant change in hematocrit was observed before and after filtration for any RBC unit. Due to different amounts of SAGM 
Table 2. In vitro RBC characteristics (mean \pm $\mathrm{SD})$ on the day of filtration after apheresis collection $^{\mathrm{a}}$

\begin{tabular}{lllll}
\hline & \multicolumn{4}{l}{ RBC apheresis collection } \\
\cline { 2 - 5 } & $\begin{array}{l}\text { Alyx } \\
(\mathrm{n}=30)\end{array}$ & $\begin{array}{l}\text { Amicus } \\
(\mathrm{n}=15)\end{array}$ & $\begin{array}{l}\text { MCS }+ \\
(\mathrm{n}=29)\end{array}$ & $\begin{array}{l}\text { Trima Accel } \\
(\mathrm{n}=25)\end{array}$ \\
\hline Hemolysis, \% & $0.04 \pm 0.01$ & $0.04 \pm 0.02$ & $0.05 \pm 0.02$ & $0.04 \pm 0.02$ \\
Supernatant $\mathrm{Hb}, \mathrm{mg} / \mathrm{ml}$ & $1.99 \pm 1.46$ & $1.72 \pm 0.89$ & $1.90 \pm 0.59$ & $1.87 \pm 1.19$ \\
Supernatant $\mathrm{K}+\mathrm{mmol} / 1$ & $1.79 \pm 0.22$ & $1.79 \pm 0.29$ & $2.01 \pm 0.53$ & $1.89 \pm 0.22$ \\
ATP, $\mu \mathrm{mol} / \mathrm{g} \mathrm{Hb}$ & $3.88 \pm 0.66$ & $3.62 \pm 0.45$ & $3.68 \pm 0.42$ & $3.59 \pm 0.54$ \\
$\mathrm{pH}\left(22^{\circ} \mathrm{C}\right)$ & $7.120 \pm 0.031$ & $7.131 \pm 0.035$ & $7.124 \pm 0.067$ & $7.144 \pm 0.030$ \\
Glucose, $\mathrm{mmol} / \mathrm{l}$ & $25.1 \pm 1.3^{\mathrm{d}}$ & $26.8 \pm 1.0$ & $25.6 \pm 0.8^{\mathrm{b}, \mathrm{d}}$ & $24.5 \pm 0.7^{\mathrm{c}, \mathrm{d}}$ \\
Lactate, $\mathrm{mmol} / \mathrm{l}$ & $2.2 \pm 0.6$ & $2.1 \pm 0.7$ & $2.4 \pm 0.5$ & $2.1 \pm 0.4$ \\
\hline
\end{tabular}

attalic letters illustrate highest value of all systems.

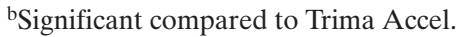

'Significant compared to MCS+.

${ }^{\mathrm{d}}$ Significant compared to Amicus. addition, mean post-filtration hematocrits were highest with TA and lowest with AM resulting in statistically significant differences between these 2 systems. The maximum percentage of RBC loss for any of the filtration procedures was observed with TA $(19.5 \%)$, the minimum with AM (1.2\%). The mean percentage of RBC and volume recovery was significantly higher for AM units, while equivalent values were observed with MCS+ and TA (except for volume recovery where TA was superior to $\mathrm{MCS}+$ ). TA presented the lowest WBC contamination of all systems by attaining the highest log reduction in WBCs, which, however, was not significant compared with the other systems. Values for PLT reduction were similar between AM and TA, while the significantly lowest values were observed with MCS+ units. All units passed the bacterial control tests after 42 days of storage.

\section{Comparison of Paired RBC Units from a Single Donation}

Only small differences in volume and hematocrit were observed in paired units. The differences were highest in TA and lowest in AX units, proving statistical significance between these 2 systems. In 31 (94\%) of the 33 2-RBCA, the difference in volume and RBC mass of the paired units was $<10 \mathrm{ml}$. One paired TA unit showed a volume difference greater than $10 \mathrm{ml}(10.4 \mathrm{ml})$, another paired TA unit differed by $23.8 \mathrm{ml}$ for RBC mass.

\section{Effects of Storage on RBC Quality}

The results of in vitro tests regarding the effect of storage on RBC quality are summarized in table 2 (day of filtration) and table 3 (storage day 42). At the beginning of storage, apart from significantly higher initial glucose concentrations observed with AM units, the parameters were similar among the RBCs. At the end of storage, TA demonstrated the lowest val- ues for hemolysis and supernatant $\mathrm{Hb}$. The rate of hemolysis was significantly lower compared to MCS+. On day 42, significantly lower potassium and ATP levels were observed with AM and AX units, respectively. TA and AX units demonstrated the highest lactate and lowest glucose levels of all systems. The differences in lactate levels reached statistical significance compared to AM and MCS+, while only the glucose concentrations of TA (not of AX) were statistically different from the other systems. The $\mathrm{pH}$ was kept above $6.5[9,10]$ in all study units until the end of storage with no significant differences between the study groups.

\section{Discussion}

This study evaluated the filtration performance and the effect of storage on the quality of leukodepleted packed RBCs derived from 66 apheresis procedures using 4 latest-generation apheresis systems. Except for 1 paired AX unit, each of the filtered RBCs $(\mathrm{n}=99)$ contained $<1 \times 10^{6}$ residual WBCs, which is the current European and German standard for leukoreduced blood products $[9,10]$. All units fulfilled the standard of the American Association of Blood Banks (AABB) of $<5.0 \times$ $10^{6}$ WBCs [13]. AX units had the highest WBC contamination of all systems, with 1 paired unit exceeding the upper European limit. This could be due to pressure filtration, as gravity filtration was used in all other procedures. Furthermore, air release of the final AX products was performed by pressing air back into the leukoreduction filter. This could result in a reflux of blood from the filter (highly contaminated with WBCs) back into the storage bag with subsequent WBC contamination of the collected RBCs. An artificial reflux of blood from the filter into the collected RBCs during air release was retrospectively identified as the explanation for the relatively high WBC content in the AX unit. A possible blood flow from the filter into the final product during air release could be avoided by placing a clamp near the leukoreduction filter. To- 
Table 3. In vitro RBC characteristics (mean \pm $\mathrm{SD})$ on day 42 of storage after apheresis collection $^{\mathrm{a}}$

\begin{tabular}{lllll}
\hline \multicolumn{4}{l}{ RBC apheresis collection } \\
\cline { 2 - 5 } & $\begin{array}{l}\text { Alyx } \\
(\mathrm{n}=30)\end{array}$ & $\begin{array}{l}\text { Amicus } \\
(\mathrm{n}=15)\end{array}$ & $\begin{array}{l}\text { MCS }+ \\
(\mathrm{n}=29)\end{array}$ & $\begin{array}{l}\text { Trima Accel } \\
(\mathrm{n}=25)\end{array}$ \\
\hline Hemolysis, \% & $0.19 \pm 0.05$ & $0.21 \pm 0.06$ & $0.21 \pm 0.06^{\mathrm{b}}$ & $0.14 \pm 0.04^{\mathrm{c}}$ \\
Supernatant $\mathrm{Hb}, \mathrm{mg} / \mathrm{ml}$ & $8.98 \pm 2.86$ & $8.48 \pm 3.84$ & $8.80 \pm 2.65$ & $6.75 \pm 2.44$ \\
Supernatant K+, mmol/1 & $51.89 \pm 4.36^{\mathrm{e}}$ & $46.01 \pm 2.79$ & $51.91 \pm 3.85^{\mathrm{e}}$ & $53.54 \pm 5.13^{\mathrm{e}}$ \\
ATP, $\mu \mathrm{mol} / \mathrm{g} \mathrm{Hb}$ & $1.68 \pm 0.35$ & $2.21 \pm 0.42^{\mathrm{d}}$ & $1,93 \pm 0.38$ & $2.11 \pm 0.34^{\mathrm{d}}$ \\
ATP, \% initial value & $43.6 \pm 7.9$ & $61.1 \pm 9.0^{\mathrm{d}}$ & $57.9 \pm 7.8$ & $59.4 \pm 12.4^{\mathrm{d}}$ \\
$\mathrm{pH}\left(22^{\circ} \mathrm{C}\right)$ & $6.523 \pm 0.049$ & $6.514 \pm 0.028$ & $6.526 \pm 0.041$ & $6.504 \pm 0.032$ \\
Glucose, $\mathrm{mmol} / 1$ & $10.2 \pm 1.5^{\mathrm{e}}$ & $12.3 \pm 1.2^{\mathrm{b}}$ & $11.5 \pm 1.4^{\mathrm{b}}$ & $8.6 \pm 1.5^{\mathrm{e}}$ \\
Lactate, $\mathrm{mmol} / \mathrm{l}$ & $27.7 \pm 2.5^{b}$ & $25.6 \pm 1.8^{\mathrm{b}, \mathrm{d}}$ & $25.0 \pm 2.7^{\mathrm{b}, \mathrm{d}}$ & $31.6 \pm 2.5^{d}$ \\
\hline
\end{tabular}

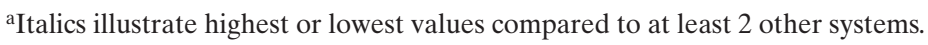

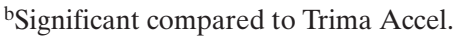

'Significant compared to MCS+.

${ }^{\mathrm{d}}$ Significant compared to Alyx.

eSignificant compared to Amicus. gether with an additional sample pouch for air release integrated in the disposable set between the storage bag and the filter, this could help avoiding the risk of WBC contamination of the collected RBCs.

To provide a valid comparison of apheresis RBCs, the factors that can affect filtration efficiency or storage quality must be equivalent. In our study, this was achieved by performing all collections with ACD-A as anticoagulant and SAGM as preservative solution. All RBCs had similar pre-filtration WBC loads and were kept at room temperature prior to filtration. Despite similar starting conditions, differences in filter performance with respect to filtration time, WBC reduction and $\mathrm{RBC}$ loss were observed. The mean time to complete filtration was shortest with $\mathrm{AX}$ and longest with $\mathrm{AM}$ and TA procedures. Again, the use of pressure filtration leading to an accelerated filter passage could explain this finding. Pre-filtration hematocrits influenced by different amounts of SAGM addition were also reported to influence filter performance [11]. Due to reduced viscosity, lower hematocrits may result in accelerated filter passage, probably coupled with reduced $\mathrm{RBC}$ loss. The analysis of paired units appeared to confirm this hypothesis. Compared to TA units demonstrating higher Hematocrits, MCS+ double units combined lower hematocrits with shorter filtration times and better $\mathrm{RBC}$ recoveries. This picture changed upon analysis of RBC-PLT units. Due to the lower hematocrits, the filtration of MCS + units was faster but resulted in lower volume recoveries compared to TA units presenting higher hematocrits. AM units containing even more SAGM as compared to MCS+ demonstrated the longest filtration times coupled with the lowest loss of volume and RBCs. Apart from different RBC viscosity, improved adherence to the filter material could also have accounted for slower filtration times and decreased filtration rates. This was underlined by the finding that log reduction in WBCs was higher in units with longer filtration times (such as TA) compared to those with shorter filtration times (such as MCS+). Our re- sults for filtration time and $\mathrm{RBC}$ loss complied favorably with previous reports on 2-RBCA performed with the MCS+ machine [14]. Despite similar filtration times, MCS+ double units attained better volume and $\mathrm{RBC}$ recoveries than $\mathrm{MCS}+$ single units. During filtration of the whole MCS+ double unit, the volume loss was divided equally between each of the obtained single units. This led to an increased volume recovery compared to single units obtained by PLT-RBC apheresis. On the other hand, WBC reduction was slightly higher in unpaired units, but this was not significant. Hence, the lower RBC loss noted with double-unit filtration could be considered as an advantage over single-unit filtration during 2-RBCA.

The RBC loss of some TA and MCS+ units exceeded 15\% which is the upper FDA (US Food and Drug Administration) limit $[3,12]$. In addition, a mean of $153 \mathrm{ml}$ of absolute RBC mass, which is the acceptable mean RBC content for leukoreduced apheresis RBCs established by the AABB standards [13], was not reached by TA and MCS+ units. Apart from differences in filter performance, this was mainly the result of an additional pre-filtration sampling loss. Without sampling, MCS+ and TA units could have been expected to comply with the required mean level for RBC mass, particularly as the displayed collection volume was close to the programmed target of $180 \mathrm{ml}$ absolute RBC mass. For TA and AM, the displayed values were checked and confirmed by pre-filtration measurements performed prior to SAGM addition $(174.1 \pm 5.3 \mathrm{ml}$ for TA single units, $182.2 \pm 4.5 \mathrm{ml}$ for AM single units, $179.6 \pm 5.8$ $\mathrm{ml}$ for TA paired units). For procedures with $\mathrm{AX}$, the filtration related volume and RBC losses could only be calculated from the displayed mean volume recovery $(89.3 \pm 0.9 \%)$, as the fully automated process inhibited pre-filtration measurements. The calculated values for filtration related volume $(33.7 \pm 0.6 \mathrm{ml})$ and $\mathrm{RBC}$ loss $(10.7 \%)$ were similar to TA, while the calculated values for pre-filtration volume $(314.7 \pm$ $5.7 \mathrm{ml}), \mathrm{RBC}$ count $\left(2.03 \pm 0.08 \times 10^{12} /\right.$ unit $)$ and absolute $\mathrm{RBC}$ mass $(179.5 \pm 6.0 \mathrm{ml})$ were significantly higher compared to 
the other systems. It has to be taken into account that calculated values that are not checked by in vitro measurements should be interpreted with caution, as inaccuracies in recording parameters, such as collection volumes or times, were reported previously with apheresis devices [15]. Comparing paired RBC units, only small differences in volumes and Hematocrits were observed. Where the volume and RBC mass deviations of paired units exceeded $10 \mathrm{ml}$ as observed in $6 \%$ of all donations, the units had been collected with the TA machine. In contrast to the other 2-RBCA systems, SAGM was added manually to each of the paired units. This could explain a greater volume difference between twin units and should prompt the manufacturer to think about further automation.

No relevant differences regarding in vitro parameters were observed among the RBCs on the day of filtration. Differences in the initial glucose concentration (highest in the AM units and lowest in the TA units) were explained by different volumes of SAGM added to the RBCs to provide glucose during storage. The in vitro data for free $\mathrm{Hb}$ obtained at the end of storage suggest that hemolysis was most likely the effect of post-filtration WBC contamination. TA units with the highest $\log$ reduction in WBCs had the lowest values for hemolysis (significantly lower than MCS+) and free $\mathrm{Hb}$ after 42 days of storage. In turn, the lowest log reduction in WBCs resulted in the highest values for free $\mathrm{Hb}$, as demonstrated with endstored AX and MCS+ units. Critical values of $>200 \mathrm{mg} / \mathrm{dl}$ for free $\mathrm{Hb}$ or $>0.8 \%$ for hemolysis $[9,10]$ were not observed in any of the units of any study group at any time of observation. The significantly lower levels of supernatant potassium observed with AM units on day 42 suggest less impairment of the $\mathrm{Na}+\mathrm{K}+$ pump due to better energy maintenance, as re- flected by the higher ATP levels. Because SAGM contains adenine as an ATP precursor, the higher initial SAGM amounts could have accounted for this finding. At storage day 42, the significantly lowest glucose levels were combined with the significantly highest lactate levels in TA and AX units. Apart from lower initial glucose concentrations, this could have been caused by an increased anaerobic glucose metabolism. As a result, ATP preservation was similar or even higher in TA units even though initial SAGM volumes were significantly smaller compared to the other systems. Despite increased glucose utilization and high initial adenine amounts, AX units had the lowest ATP preservation. This was probably the result of more contaminating WBCs which also consume ATP during storage. Except for some AX units, a minimum of $1.5 \mu \mathrm{mol}$ ATP per $\mathrm{g} \mathrm{Hb}$, described as critical for sufficient survival rates of transfused RBCs [16], was maintained during the entire storage period. ATP levels of $>70 \%$ of the initial value are also being discussed for sufficient 24-hour survival rates of transfused RBCs. As illustrated in table 3, our 42-day ATP levels were in accordance with previously published values of $60-68.5 \%$ of the initial value in end-stored RBCs [17]. Notably, none of the study units maintained values of $>70 \%$ at this observation time. While AX units fell below this level after only 3 weeks of storage, units of the other systems maintained it for at least 5-6 weeks (TA, AM) and 4-5 weeks (MCS+), respectively. In conclusion, this study showed that $\mathrm{RBC}$ apheresis resulted in units with sufficient PLT and WBC reduction and satisfactory in vitro qualities after 42 days of storage. WBC contamination of AX units should be decreased to better comply with European requirements for leukoreduced blood products and to preserve sufficient ATP amounts at the end of shelf life.

\section{References}

1 Moog R: Implementation of concurrent red blood cell and platelet collection by apheresis in a university haemapheresis unit. Transfus Med 2004;14: 145-150.

2 Zinsgem J, Moog R: Preparative haemapheresis and donor safety. Transfus Med Hemother 2004;31: 5-6.

>3 Snyder EL, Elfath MD, Taylor H, Rugg N, Greenwalt TJ, Baril L, Whitley P, Brantigan B, Story K: Collection of two units of leukoreduced RBCs from a single donation with a portable multiplecomponent collection system. Transfusion 2003;43: 1695-1705.

4 Popovsky MA: Multicomponent apheresis blood collection in the United States: current status and future directions. Transfus Apher Sci 2005;32: 299-304.

5 Valbonesi M, Giannini G, Morelli R, Frisoni R, Capra C: Multicomponent collection as of 2005. Transfus Apher Sci 2005;32:287-297.

6 Popovsky MA: Complications of blood donation: manual and automated collection precedures. Transfus Med Hemother 2004;31:49-53.
7 Wiltbank T: Donor reaction rates: a preliminary comparison of automated vs. whole blood procedures. Transfusion 2002;42(suppl):67S.

$\checkmark 8$ Smith JW, Gilcher RO: Red blood cells, plasma, and other new apheresis-derived products: improving product quality and donor utilization. Transfus Med Rev 1999;13:118-123.

9 Guide to the Preparation, Use and Quality Assurance of Blood Components. Strasbourg, France, Council of Europe Press, 2002

10 Guidelines for the Collection of Blood Components and the Usage of Blood Products (Hemotherapy). Rev ed, Bundesärztekammer and the Paul-Ehrlich-Institut. Cologne, Germany, Deutscher Ärzteverlag, 2005, in press.

11 Schlenke P: Leukocyte reduction in blood component supply: the impact of flow cytometry in assessing residual leukocytes. Transfus Med Hemother 2005;32:12-19.

12 Picker SM, Stürner S, Oustianskaja L, Gathof BS: Leukodepletion leads to component-like storage stability of whole blood - suggesting its homologous use? Vox Sang 2004;87:173-181.
13 Fridey J (ed): Standards for Blood Banks and Transfusion Services. 22nd ed, Bethesda, American Association of Blood Banks, 2003.

14 Bandarenko N, Rose M, Kowalsky RJ, Baston RK, Brecher ME, Elfath MD, Whitley P, Heminway M, Holme S: In vivo and in vitro characteristics of double units of RBCs collected by apheresis with a single in-line WBC-reduction filter. Transfusion 2001; 41:1373-1377.

15 Bueno JL, Garcia F, Castro E, Area L, Gonzalez $\mathrm{R}$ : A randomized crossover trial comparing three plateletpheresis machines. Transfusion 2005;45: 1373-1381.

16 Beutler E, Wood L: The in vivo regeneration of red cell 2.3-diphosphoglycerate after transfusion of stored blood. J Lab Clin Med 1969;74:300-304.

17 Technical Manual. 14th ed, Bethesda, American Association of Blood Banks, 2002. 